\title{
Interannual Variation of Bivalve Populations on Temperate Tidal Flats
}

\author{
Dai Miyawaki and Hideo Sekiguchi* \\ Faculty of Bioresources, Mie University, Kamihama, Tsu, Mie 514-8507, Japan \\ (Received July 22, 1998)
}

\begin{abstract}
Studies were undertaken on long-term fluctuations of densities of different life stages (planktonic larvae, new settlers, and small and large bivalves) of three bivalve species (Ruditapes philippinarum, Musculista senhousia, Nuttallia olivacea) common on tidal flats, based on samples collected for 7 years from 1990 to 1996 in the Shitomo and Ano Rivers along the west coast of Ise Bay, central Japan. Seasonal and interannual variations in densities of different life stages for the three species were remarkable. In general, seasonal variations in densities of planktonic larvae corresponded to those of the benthic populations for each species, while interannual variations in densities of the larvae did not correspond to those of the benthic populations. However, 'great' peaks of densities of the larvae sometimes contributed to establish the benthic populations of each species.
\end{abstract}

Key words: interannual variation, bivalve populations, tidal flat

As reviewed in Underwood \& Fairweather, ${ }^{1)}$ Hall ${ }^{2)}$ and Olafsson et al., ${ }^{3)}$ recent works on marine benthic invertebrates have emphasized the role of larval recruitment processes in the population dynamics and community structure of intertidal and subtidal organisms with a complex life cycle including planktonic and benthic life phases. Few works have been done on larval recruitment processes in the marine environment, probably due to difficulties in identifying planktonic larvae $\mathrm{e}^{4)}$ and in examining their transport and/or dispersal coupling with oceanographic conditions. ${ }^{5}$ However, the role of larval recruitment in the population dynamics and community structure of marine benthic invertebrates is the subject of active research today..$^{6-11)}$

Similar studies on intertidal organisms indicate that their distribution and abundance, especially for barnacles, is determined mainly by post-settlement processes when the settlement rate is high, whereas it is determined by spatial and temporal variations in settlement when the settlement rate is low. ${ }^{9,12-16)}$ Unfortunately, very few works have been done on larval recruitment processes in bivalve assemblages except Bachelet, ${ }^{17}$ and works by Sekiguchi and his colleagues. ${ }^{4,18-20)}$

We have carried out a seven-year investigation (1990 to 1996) of larval recruitment processes in bivalve assemblages on tidal flats of Ano and Shitomo Rivers in Mie Prefecture along the Pacific coast of central Japan. Our previous studies done on the flats were based on samples collected from 1990 to 1993 and have been published in Sakai and Sekiguchi, ${ }^{4)}$ Sekiguchi et al.. ${ }^{18}$ ) Tsutsumi and Sekiguchi. ${ }^{19,20)}$ These studies mainly dealt with larval recruitment processes by which spatial distributions of three species (Ruditapes philippinarum, Musculista senhousia, Nuttallia olivacea) are maintained. In the present study, we try to make clear larval recruitment processes coupling with long-term fluctuations in densities of different life stages of the above three species, absolutely dominant on the flats. Fortunately, it is now easy to identify, to a specific level, both the planktonic and settled larvae of bivalves common on intertidal and subtidal flats in central Japan according to Sakai and Sekiguchi. ${ }^{4)}$

\section{Materials and Methods}

\section{Study Area}

Ano and Shitomo Rivers, located in Tsu city, flow into the western part of Ise Bay along the Pacific coast of central Japan (Fig. 1). These rivers are small and short; Ano River runs a distance of $27.9 \mathrm{~km}$ and passes through the lowlands of Tsu city, whereas Shitomo River, with a length of $14.5 \mathrm{~km}$, passes through rice fields. Saline water

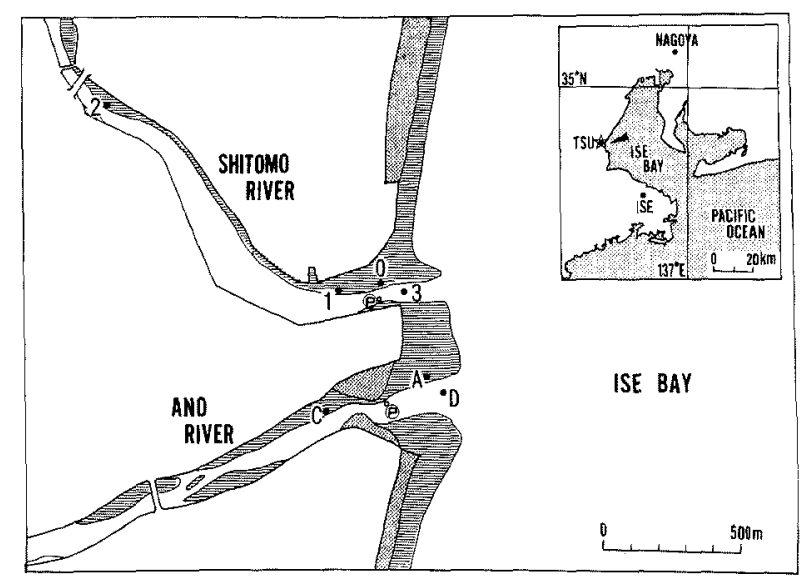

Fig. 1. Study area and location of sampling stations.

Solid circles: sampling stations, $0-3$ and A-D: sampling stations for collecting sediment, $P$ : sampling station for collecting planktonic larvae using submersible pumping gear, dotted areas: sediment exposed during the high water of spring tide, hatched areas: sediment of the intertidal zone.

\footnotetext{
*E-mail sekiguch@bio.mie-u.ac.jp
} 
is detectable from the river mouth to a weir $2.3 \mathrm{~km}$ upstream in Ano River, and from the mouth to a point 5.5 $\mathrm{km}$ upstream in Shitomo River.

Despite the mouths of the above two rivers being adjacent to each other, sediment types of tidal flats at the two river mouths are different. In general, the grain size of the sediment is smaller, and the silt-clay content is clearly higher in Shitomo River than in Ano River. ${ }^{21,22 \text { ) }}$

\section{Sampling and Data Processing}

Sampling was done on the flats of Ano and Shitomo Rivers for seven years from April 1990 to December 1996. For sampling of bivalves in the benthic phase on the tidal flats, we set up three sampling stations (Stns.A,C,D) on Ano River flat and four stations (Stns.0,1,2,3) on Shitomo River flat. The sediment at two (Stns.3,D) of the above stations was always under water of some tens of centimeters depth even when the spring tide was out (Fig. 1), while all stations were under water when the neap tide was out or when we had heavy precipitation due to a typhoon approaching Tsu city. In addition to these sampling stations, we set up two stations (Stn.P) for sampling planktonic larvae of bivalves at the mouths of the two rivers (Fig. 1).

Since we collected bivalves in a variety of pre- and postsettlement phases, i.e., planktonic larvae, new settlers, or small and large bivalves, various types of sampling gear were used in the present study as described below. Planktonic larvae were defined as veliger larvae excluding D-shaped larvae, i.e., so-called Umbo larvae. New settlers were defined as settled individuals with shell lengths less than $0.3 \mathrm{~mm}$, because shell lengths among the bivalves common on tidal flats in Japan have been known to reach ca. $200-300 \mu \mathrm{m}$ very shortly after planktonic larvae settle on the bottom sediment. ${ }^{4,23)}$ Small bivalves were defined as individuals with shell lengths ranging from $0.3 \mathrm{~mm}$ to less than $1.0 \mathrm{~mm}$, while large bivalves had shell lengths of 1.0 $\mathrm{mm}$ or more.

Definitions of 'recruitment' vary depending on research fields and/or target species. ${ }^{1)}$ In the present study, we defined 'recruitment' as individuals getting shell lengths of $1.0 \mathrm{~mm}$ or more. Definitions of recruitment in marine organisms vary among different taxa, but it is well known that higher mortality occurs shortly after planktonic larvae settle on the bottom sediment, followed by a relative constant and low mortality. ${ }^{24)}$ Higher mortality shortly after larval settlement has also been confirmed for several species of bivalves. ${ }^{25}$ )

For sampling planktonic larvae of bivalves, we collected the larvae at Stn.P once a week from February 1991 to December 1996. The samples were obtained by pumping $95 l$ of water from an intermediate depth $(1.0 \mathrm{~m})$ during the flood tide in order to avoid surface freshwater, and then filtered with a $45 \mu \mathrm{m}$ mesh sieve. The samples were fixed immediately with $5 \%$ neutral formalin seawater. The temperature and salinity of the pumped-up water were monitored with a salinometer (Salt-Meter NS-3P). In the laboratory, all specimens of planktonic veliger larvae of bivalves (excluding D-shaped veligers because of the difficulty in identifying them to a specific level) were sorted using a suction device under a dissecting microscope, ${ }^{26)}$ identified to a specific level according to Sakai and Sekiguchi, ${ }^{4)}$ and counted for each species under a microscope.
For sampling new settlers and small bivalves, we collected sediment at Stns. A,C,D and at Stns. $0,1,2,3$ once a week from April 1990 to December 1996. According to studies done previously in the present study area, ${ }^{4}$ new settlers and small bivalves were largely aggregated within the upper $1.0 \mathrm{~cm}$ of the sediment. Two sediment samples were obtained at each station during the ebb tide using a core sampler $(3.4 \mathrm{~cm}$ in diameter, $1.0 \mathrm{~cm}$ depth) for collecting surface sediment, and then filtered with a $125 \mu \mathrm{m}$ mesh sieve. The samples were fixed immediately with $5 \%$ neutral formalin seawater dyed with Rose Bengal to facilitate sorting specimens of new settlers. In the laboratory, all specimens of bivalves were sorted using a suction device, ${ }^{26)}$ identified to a specific level, and counted for each species under a dissecting microscope. Shell lengths of the specimens were measured to the nearest $1.0 \mu \mathrm{m}$ using an ocular micrometer. Specimens of new settlers and small bivalves were identified according to Sakai and Sekiguchi. ${ }^{4)}$

For sampling large bivalves, we collected sediment at Stns, A, C,D and at Stns.0,1,2,3 once a month from April 1990 to December 1996. Two sediment samples were obtained at each station during the ebb tide using a core sampler $(15.5 \mathrm{~cm}$ in diameter, $20.0 \mathrm{~cm}$ depth), and then filtered with a $1.0 \mathrm{~mm}$ mesh sieve. The samples were fixed immediately with $5 \%$ neutral formalin seawater. All specimens of bivalves were sorted, identified to a specific level, and each species was counted. Shell lengths of the specimens were measured to the nearest $0.1 \mathrm{~mm}$ using a slide caliper.

For monitoring extreme sampling bias due to patchy distribution in estimating densities of bivalves in the benthic phase, two samples were obtained at each station. Trends of density variations were similar between these two samples at each station, so we used the data for the sample with higher densities at each station.

Bivalve assemblages on the tidal flats of the present study area were absolutely dominated by the three species (Ruditapes philippinarum, Musculista senhousia, Nuttallia olivacea) as referred to later in detail. The former two species were abundant in the Shitomo flat while those were scare in the Ano flat. The reverse was true for the later species. Accordingly, shell length data were compiled for all specimens of $R$. philippinarum and $M$. senhousia obtained in the Shitomo flat, while the data of $N$. olivacea were compiled for all specimens obtained in the Ano flat. Based on shell length data of the three groups (new settlers, small and large bivalves) of these three species, different cohorts in each group were identified by applying Akamine's method $^{27)}$ that separates the polymodal length distribution into two or more normal distributions. Then, growth curves of different cohorts were inferred by following the mean shell length of the obtained normal distributions in each group.

\section{Results}

\section{Ruditapes philippinarum}

1. Planktonic larvae (Figs. 2, 3). No significant difference in density was found between the rivers for six years from 1991 to 1996 except for the year 1995 when densities of the larvae were extremely low. Seasonal variations in density were remarkable, the density being higher in spring (March to May) to early summer (June to August) and in 


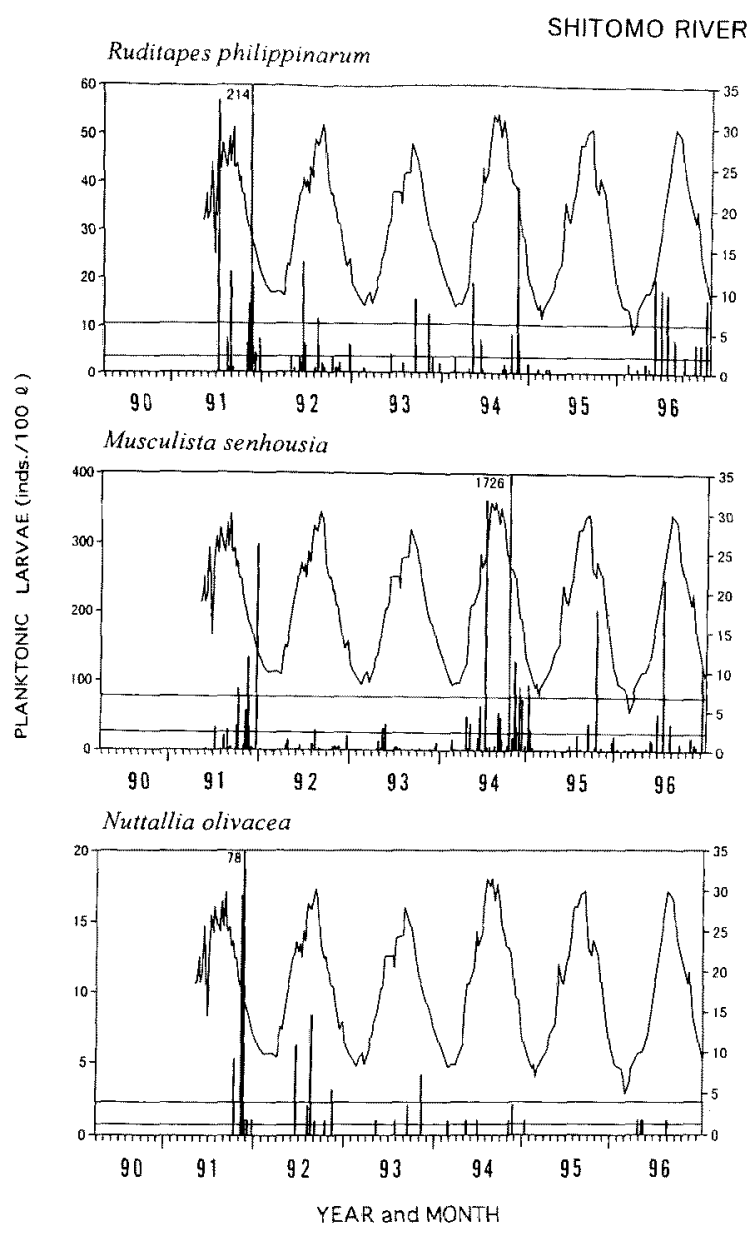

Fig. 2. Seasonal and interannual variations in densities of planktonic larvae of Ruditapes philippinarum, Musculista senhousia and Nuttallia olivacea in Shitomo River.

Solid bars: densities of the larvae, solid curves: water temperature, lower horizontal lines: total averages of densities of the larvae, upper horizontal lines: densities three times as the total averages.

fall (September to November) every year, but being much higher in the fall. Interannual variations in density were notable, the density in the fall of 1991 reaching over 200 inds. / $100 l$ (295 inds./ $100 l$ in Ano River and 214 inds./ $100 \mathrm{l}$ in Shitomo River), while densities of the larvae were extremely lower in the year 1995.

2. New settlers (Fig. 4a). No significant difference in density was found between tidal flats of the rivers for seven years from 1990 to 1996. Seasonal variations in density were remarkable, the density being higher in the summer to winter every year. Interannual variations in density were notable, the density reaching over 10 inds. $/ \mathrm{cm}^{2}$ on flats of the rivers in fall to winter of 1991 . Higher densities of new settlers generally corresponded to those of planktonic larvae. However, densities of planktonic larvae in the year 1994 became relatively lower while those of new settlers were much higher with density of 5 inds. $/ \mathrm{cm}^{2}$.

3. Small bivalves (Fig. 4b). No significant difference in density was found between tidal flats of the rivers for seven years from 1990 to 1996 . Seasonal and interannual variations in density were not so remarkable as for new set-

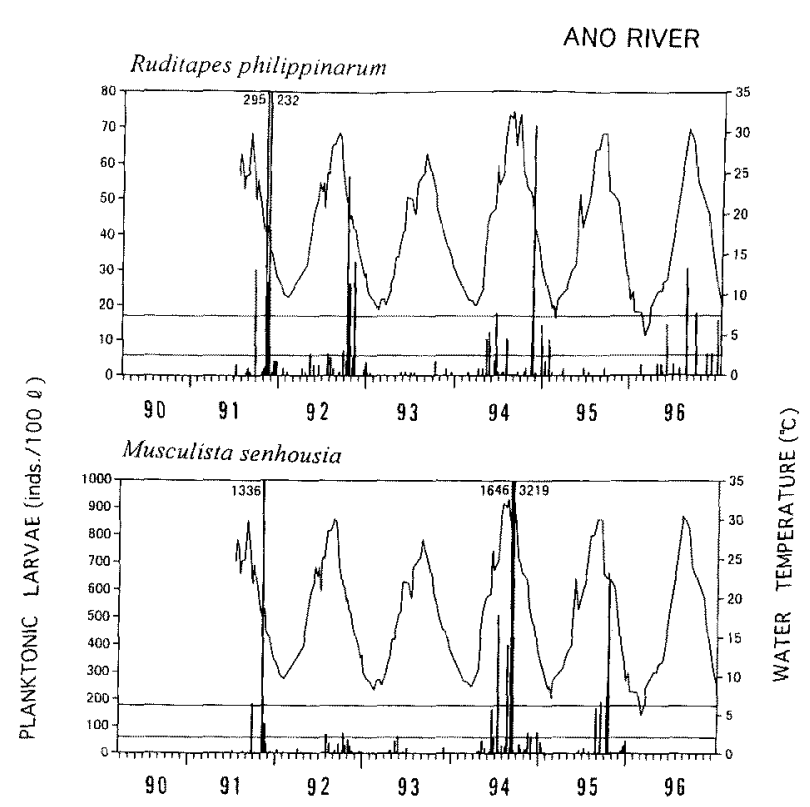

Nuttallia olivacea



Fig. 3. Seasonal and interannual variations in densities of planktonic larvae of Ruditapes philippinarum, Musculista senhousia and Nuttallia olivacea in Ano River.

Symbols are same as in Fig. 2.

tlers, the higher density occurring shortly following that of new settlers, and reaching over 10 inds. $/ \mathrm{cm}^{2}$ in winter (January to February 1995). Higher densities of planktonic larvae in fall to winter of 1991 corresponded to those for new settlers and small bivalves in the spring of 1992 . However, densities of planktonic larvae in fall of 1994 were lower than in the fall of 1991, while the reverse was the case for small bivalves.

4. Large bivalves (Fig. 4c). The density on the Shitomo flat was in general nearly three times as high as that on the Ano flat, but higher densities were found on the Ano flat for three years of 1990, 1992 and 1995. Seasonal variations in density were remarkable on the Shitomo flat, the density generally being higher in summer to fall every year. Interannual variations in density were notable on the Shitomo flat. Higher densities of large bivalves in the fall of 1992 (30,000 inds. $/ \mathrm{m}^{2}$ on Shitomo flat) corresponded to those of new settlers and small bivalves in spring of 1992 and also to those of planktonic larvae in the fall of 1991, while those in summer of $1994\left(20,000\right.$ inds. $/ \mathrm{m}^{2}$ on the Shitomo flat) corresponded to those of new settlers and small bivalves in the summer of 1994 .

5. Cohort analyses (Fig. 7). A total of 37 cohorts (A-Z, a-k,omitting E,I,J) were identified throughout seven-year 
a Ruditapes philippinarum

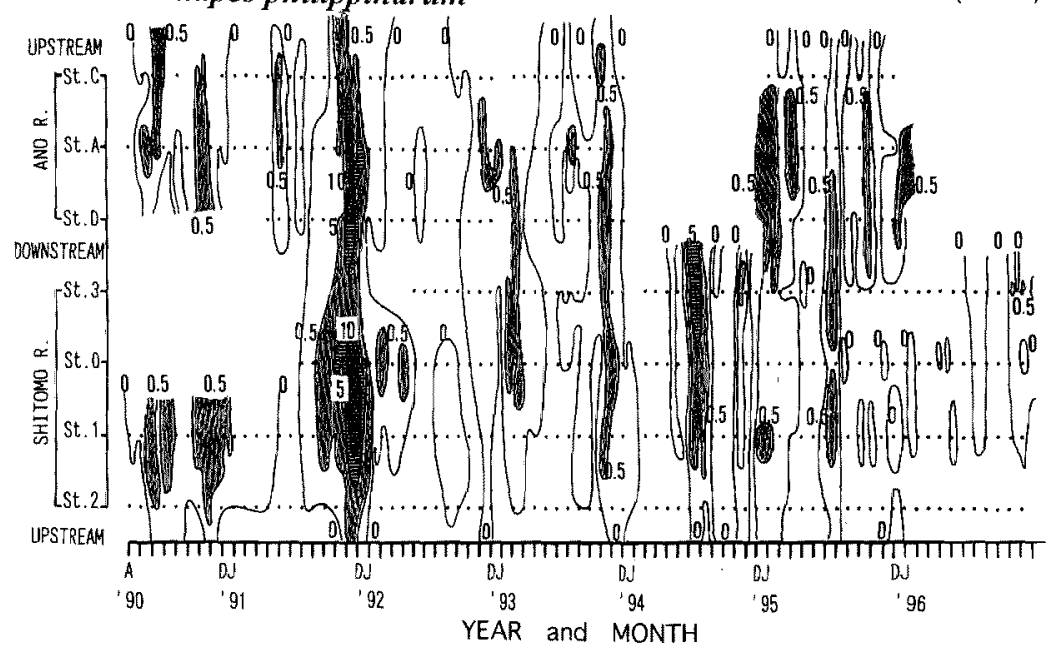

b Ruditapes philippinarum

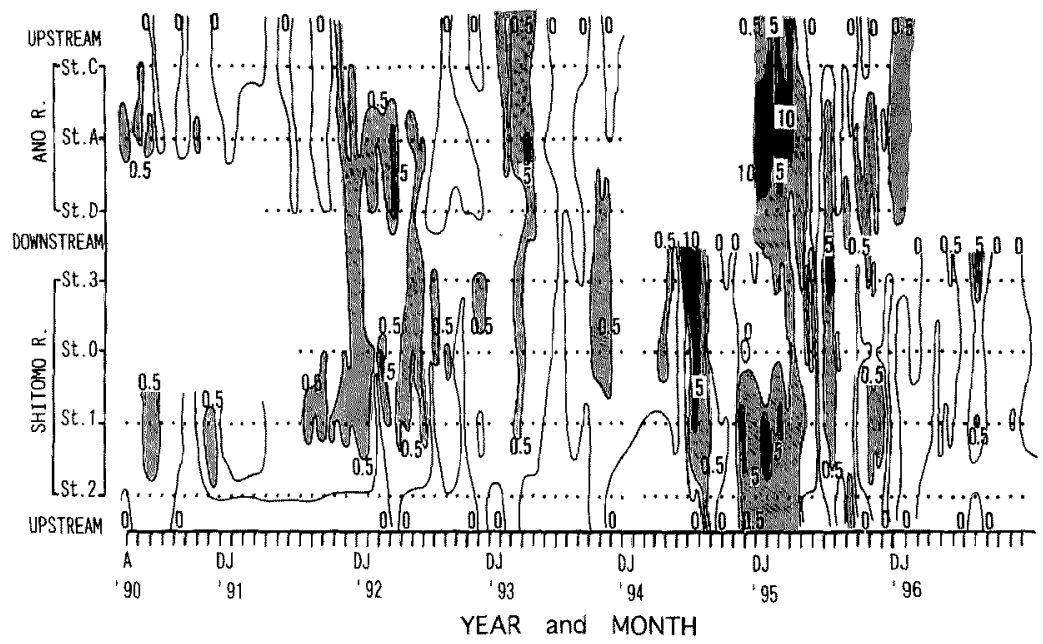

C Ruditapes philippinarum

LARGE BIVALVES (inds./m2)



Fig. 4. Spatial and temporal distributions of Ruditapes philippinarum densities on tidal flats of Shitomo and Ano Rivers.

a: new settlers, b: small bivalves, c: large bivalves, solid dots: samples collected, but the dots omitted between dots in the figure for new settlers and small bivalves. 
investigation from 1990 to 1996 . The cohorts (A-K) were identified based on specimens collected at Stn.1 on the Shitomo flat where densities of newly settlers, and small and large bivalves were much higher than at any other stations as shown in Fig. 4. On the other hand, the cohorts (L-Z, a-k) were identified based on all specimens collected at all stations on the Shitomo flat because densities of new settlers, and small and large bivalves were much higher on the Shitomo flat than on the Ano flat as shown in Fig. 4. Then, the two cohorts $\left(G, G^{\prime}\right)$ probably belong to the same one. The two cohorts $(\mathrm{A}, \mathrm{B})$ would be derived from those succeeding in recruiting to the benthic populations in the year 1989 before the present study started.

of the above 37 cohorts, a total of 22 cohorts (A$\mathrm{C}, \mathrm{G}, \mathrm{H}, \mathrm{K}, \mathrm{L}, \mathrm{N}, \mathrm{O}, \mathrm{Q}-\mathrm{V}, \mathrm{X}-\mathrm{Z}, \mathrm{c}, \mathrm{f}, \mathrm{i}, \mathrm{j})$ succeeded in recruiting to the benthic populations (Fig.7). These cohorts are divided into two groups: the one group includes the cohorts $(\mathrm{C}, \mathrm{H}, \mathrm{R}-\mathrm{T})$ with their larvae settling in spring to summer, recruiting within three months after larval settling, and disappearing within three months after individual recruiting probably due to high precipitation, while the other group includes the cohorts $(\mathrm{G}, \mathrm{K}, \mathrm{L}, \mathrm{O}, \mathrm{Q}, \mathrm{U}-\mathrm{Z}, \mathrm{f}, \mathrm{j})$, with their larvae settling in fall to winter and then recruiting in spring of the following year (i.e. within five months after settling). The cohorts (D,F, J,M,a,b,d,e,g,h) settled but failed to recruit.

Occurrence periods of cohorts markedly varied depending on cohorts, seasons and years. These were in the range of three to five months for the cohorts settling in spring to summer and recruiting in summer to fall of the same year (Fig. 7). On the other hand, they were in the range of six to twenty two months for the cohorts settling in fall to winter and recruiting in spring of the following year (Fig. 7).

The benthic populations of the species in the present study area were mainly sustainable by the cohorts that settled in fall to winter and then recruited in spring of the following year.

\section{Musculista senhousia}

1. Planktonic larvae (Figs. 2, 3). No significant difference in density was found between the rivers for the six years from 1991 to 1996 . Seasonal variations in density were remarkable, the density being higher in summer to fall every year except the year 1994 when the larvae occurred throughout the year. Interannual variations in density were notable, the density reaching 1,336 inds./ $100 \mathrm{l}$ in Ano River (298 inds. $/ 100 l$ in Shitomo River) in the fall of $1991,3,219$ inds. / $100 l$ in Ano River $(1,726$ inds. $/ 100 l$ in Shitomo River) in summer of 1994 , and 665 inds. $/ 100 \mathrm{l}$ in Ano River (204 inds./ $100 l$ in Shitomo River) in the fall of 1995. Particularly, for the two years from 1992 to 1993 , the density was much lower as contrasted to that of the other years.

2. New settlers (Fig. 5a). No significant difference in density was found between tidal flats of the two rivers for seven years except the year 1991 when the density was higher on the Shitomo flat than on the Ano flat. Seasonal variations in density were remarkable, the density being higher in summer to fall every year. Interannual variations in density were notable, the density reaching over 20 inds. $/ \mathrm{cm}^{2}$ on the Shitomo flat (over 0.5 inds. $/ \mathrm{cm}^{2}$ on the Ano flat) in the fall of 1991 , over 5 inds. $/ \mathrm{cm}^{2}$ on the Shito- mo flat in the summer of 1994 and over $5 \mathrm{inds} . / \mathrm{cm}^{2}$ on both flats in summer to fall of 1995, and corresponding to higher densities of planktonic larvae. For the two years from 1992 to 1993 when densities of planktonic larvae were significantly lower than in the other years, those of new settlers were also much lower with less than 0.5 inds./ $\mathrm{cm}^{2}$.

3. Small bivalves (Fig. 5b). No significant difference in density was found between tidal flats of the two rivers for seven years except for 1991 and 1995 when the density was higher on the Shitomo flat than on the Ano flat. Seasonal and interannual variations in density were not so remarkable as for new settlers. Higher densities of small bivalves generally occurred shortly following those of new settlers, those in the fall of 1991 (over 5 inds. $/ \mathrm{cm}^{2}$ on both flats), in summer of 1994 (200 inds. $/ \mathrm{cm}^{2}$ on the Shitomo flat) and in summer to fall of 1995 ( 50 inds. $/ \mathrm{cm}^{2}$ on the Shitomo flat and over 5 inds. $/ \mathrm{cm}^{2}$ on Ano flat) corresponding to those of planktonic larvae, while for 1992 and 1993 when densities of the larvae were much lower densities of new settlers and also small bivalves were much lower as contrasted to those in the other years.

4. Large bivalves (Fig. 5c). Significant difference in density was found between tidal flats of the two rivers except for the three years from 1994 to 1996 , the density generally being much higher on the Shitomo flat than on the Ano flat. Seasonal variations in density were remarkable on the Shitomo flat, the density being higher in summer to fall every year but decreasing in winter. Interannual variations in density were notable, the higher densities corresponding to those of small bivalves. The higher densities $(10,000$ inds./ $\mathrm{m}^{2}$ on the Shitomo flat and over 50 inds. $/ \mathrm{m}^{2}$ on the Ano flat) in fall of 1991 corresponding to those of new settlers and small bivalves in fall of 1991, and also to those of planktonic larvae in fall of 1991, while those in summer of 1994 and $1995\left(70,000\right.$ and 50,000 inds. $/ \mathrm{m}^{2}$ on the Shitomo flat, and 50,000 inds. $/ \mathrm{m}^{2}$ on the Ano flat, respectively) correspond to those of new settlers and small bivalves in the same period.

5. Cohort analyses (Fig. 7). A total of 49 cohorts (A-O, $\mathrm{d}-\mathrm{w}$, omitting the other cohorts) were identified throughout seven-year investigation from 1990 to 1996 . The cohorts $(\mathrm{A}-\mathrm{H})$ were identified based on specimens collected at Stn.l of the Shitomo flat where densities of new settlers, and small and large bivalves were much higher than at any other station as shown in Fig. 5. On the other hand, the cohorts (I-O,d-w) were identified based on all specimens collected at all stations on the Shitomo flat because densities of new settlers, and small and large bivalves were much higher on the Shitomo flat than on the Ano flat as shown in Fig. 5. In the year 1992, it was difficult to identify any cohort because densities of new settlers, and small and large bivalves were extremely low (Fig. 5).

Of the above 49 cohorts, a total of 22 cohorts (A,B, G,I$\mathrm{O}, \mathrm{d}-\mathrm{f}, \mathrm{h}, \mathrm{i}, \mathrm{m}, \mathrm{n}, \mathrm{p}, \mathrm{r}, \mathrm{s}, \mathrm{u})$ succeeded in recruiting to the benthic populations. The cohorts (A,B,F, G, I, K-M, h, i, r,s, u) settled in spring to summer and recruiting within two months, while the cohorts $(C-E, H, g, j-1, n)$ settled in fall to winter but failed to recruit.

Occurrence periods of cohorts markedly varied depending on cohorts, seasons and years: those were in the range of two to eight months for the cohorts, their larvae settling 

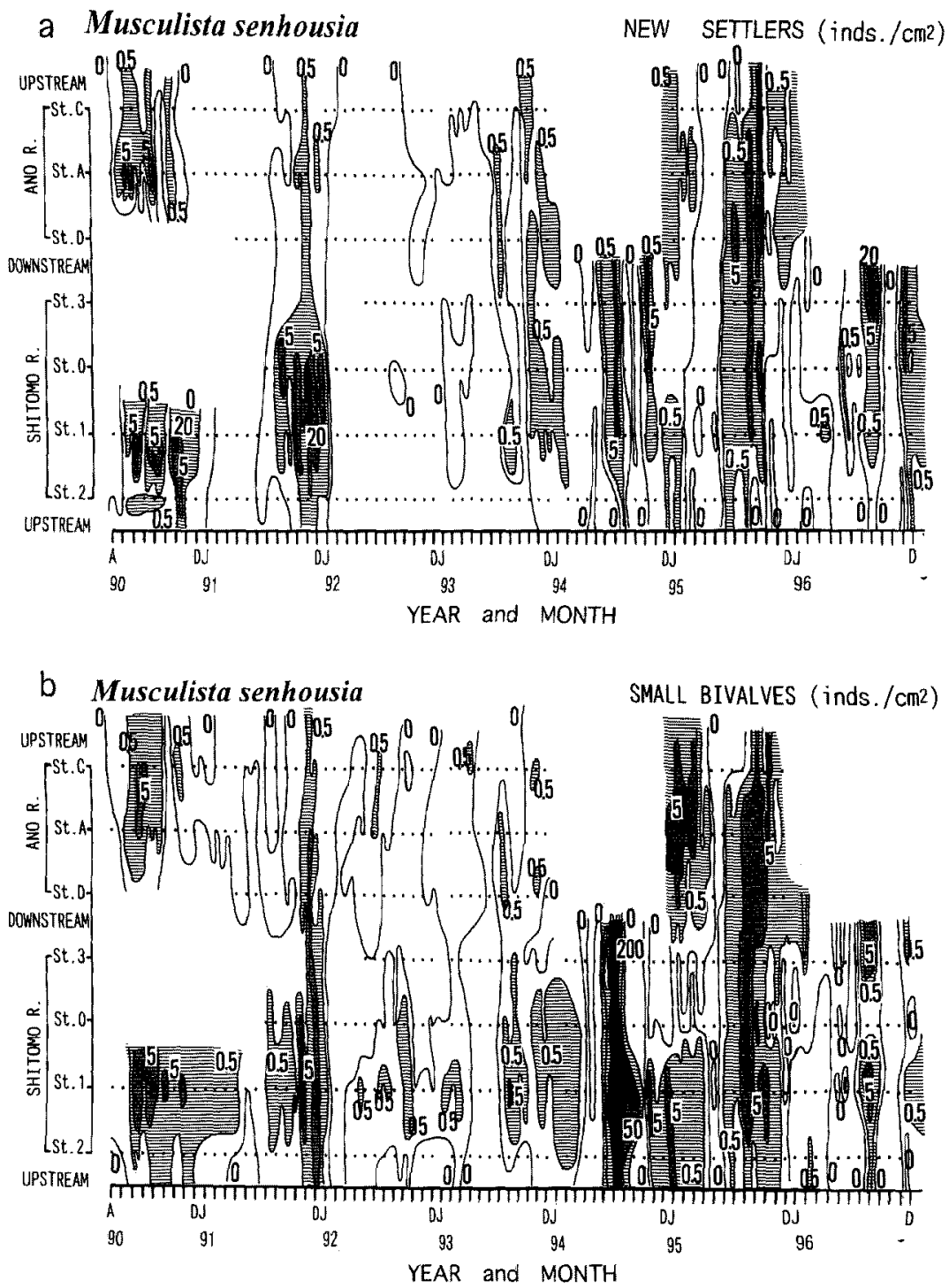

\section{Musculista senhousia}

LARGE BIVALVES (inds./m2)

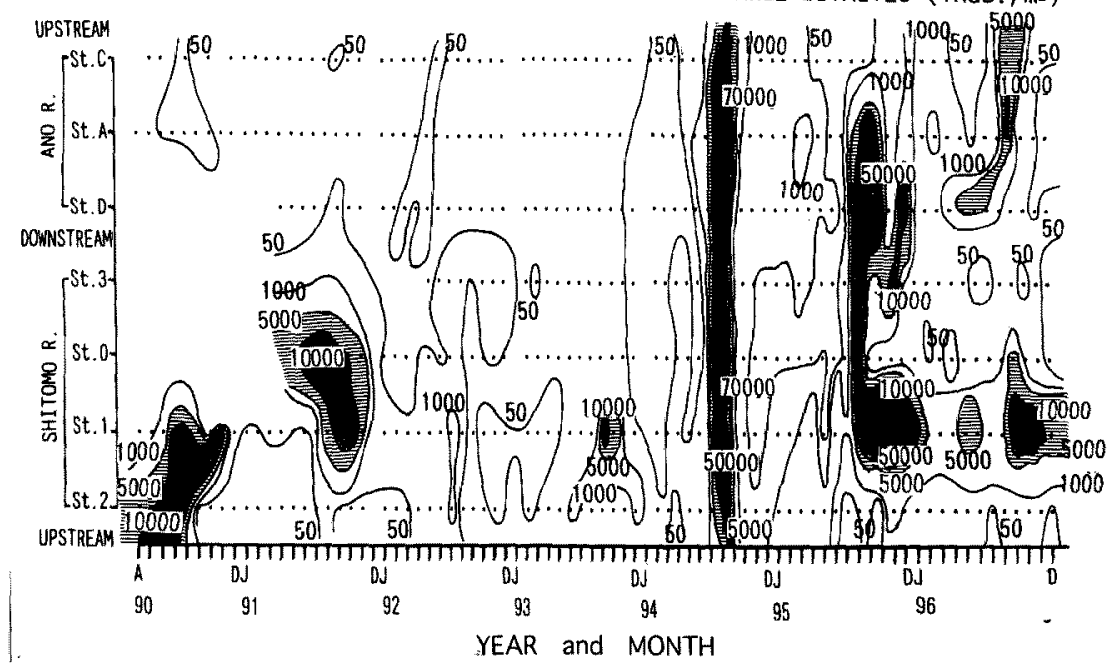

Fig. 5. Spatial and temporal distributions of Musculista senhousia densities on tidal flats of Shitomo and Ano Rivers. Symbols are same as in Fig. 4. 



Fig. 6. Spatial and temporal distributions of Nuttallia olivacea densities on tidal flats of Shitomo and Ano Rivers. Symbols are same as in Fig. 4. 
in spring to summer and recruiting to the populations in summer to fall in the same year, while those were in the range of one to six months for the cohorts, their larvae settling in fall to winter and recruting in fall to winter of the same year (Fig. 7). Furthermore, the number of cohorts with success and/or failure in recruitment markedly varied depending on the sampling year, so that seasonal and interannual variations in density were remarkable for new settlers, and small and large bivalves as shown in Fig. 5.

The benthic populations of the species in the present study area were mainly sustainable by the cohorts, their larvae settling in the summer and recruiting in summer to fall of the same year.

\section{Nuttallia olivacea}

1. Planktonic larvae (Figs. 2, 3). No significant difference in density was found between the two rivers for six years from 1991 to 1996 . Seasonal variations in density were remarkable, the density being higher in fall to winter every year but decreasing in spring except for the year 1992 when the larvae occurred also in summer. Interannual variations in density were notable, the density reaching 78 inds. $/ 100 l$ in Shitomo River (53 inds. $/ 100 l$ in Ano River) in fall to winter of 1991 while the larvae were not collected in the year 1995.

2. New settlers (Fig. 6a). No significant difference in density was found between tidal flats of the rivers for seven years from 1990 to 1996 except the year 1991 when the density was higher on the Ano flat than on the Shitomo flat. Seasonal variations in density were remarkable, the density being higher in fall to winter every year. Interannual variations in density were notable, the density reaching over 10 inds. $/ \mathrm{cm}^{2}$ on the Ano flat (over 0.5 inds. $/ \mathrm{cm}^{2}$ on the Shitomo flat) in the fall of 1991. Higher densities of new settlers generally corresponded to those of planktonic larvae, while in the year 1995 when the larvae were not collected, densities of new settlers also were much lower with less than 0.5 inds. $/ \mathrm{cm}^{2}$ on both flats as contrasted to that in the other years.

3. Small bivalves (Fig. 6b). Significant difference in density was found between tidal flats of the two rivers for seven years from 1990 to 1996 , the density generally being much higher on the Ano flat than on the Shitomo flat. Seasonal and interannual variations in density were not remarkable as for new settlers. Higher densities of small bivalves generally occurred shortly following those of new settlers, for example, those of planktonic larvae with 53 inds. $/ 100 l$ in Ano River (78 inds. / $100 l$ in Shitomo River) and of new settlers with 10 inds. $/ \mathrm{cm}^{2}$ on the Ano flat (over $0.5 \mathrm{inds} . / \mathrm{cm}^{2}$ on the Shitomo flat) in the fall of 1991 corresponding to those of small bivalves in January and onward in 1992, while for two years of 1995 and 1996 when the densities of the larvae was much lower, those of new settlers and small bivalves were much lower as contrasted to those in the other years.

4. Large bivalves (Fig. 6c). Significant difference in density was found between tidal flats of the two rivers for seven years from 1990 to 1996 , the density generally being much higher on the Ano flat than on the Shitomo flat. Seasonal variations in density were remarkable on the Ano flat, the density being higher in summer to fall every year. Interannual variations in density were notable, the higher
SHITOMO RIVER
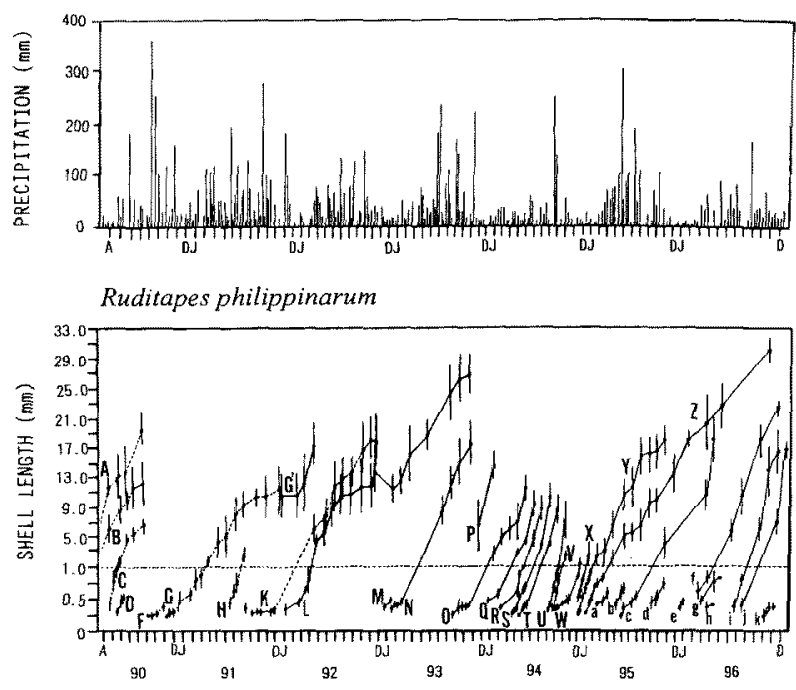

Musculista senhousia



Fig. 7. Cohorts of Ruditapes philippinarum and Musculista senhousia populations on tidal flats of Shitomo and Ano Rivers.

Dotted and solid curves in lower two figures: cohorts identified using specimens obtained at stn. 1 and those obtained at all stations on Shitomo River flat, respectively, alphabets: different cohorts, horizontal dotted lines: indicating that different cohorts succeed to recruite when getting $1.0 \mathrm{~mm}$ or more shell length. Shell-length scale is different bordered at $1.0 \mathrm{~mm}$.

densities corresponding to those of small bivalves. Higher densities $\left(10,000\right.$ inds. $/ \mathrm{m}^{2}$ on the Ano flat, 1,000 inds. $/ \mathrm{m}^{2}$ on the Shitomo flat) of large bivalves in summer of 1992 corresponded to those of small bivalves in winter (December 1991) to the spring of 1992 and to those of new settlers in fall of 1991, while for two years of 1995 and 1996 when densities of the larvae were extremely lower those of large bivalves as well as of new settlers and small bivalves were much lower as contrasted to those in the other years.

5. Cohort analyses (Fig. 8). A total of 16 cohorts (A-P) were identified throughout five-year investigation from 1992 to 1996 (for two years from 1990 to 1991 , data on shell lengths of the species were lost). The cohorts (A,C,F$\mathrm{P})$ were identified based on specimens collected at all stations on the Ano flat where densities of new settlers, and small and large bivalves were much higher than on the Shitomo flat as shown in Fig. 6. On the other hand, the cohorts $\left(C^{\prime}, D, E\right)$ identified based on specimens collected at Stn.C on Ano flat, where densities of large bivalves were higher than at any other station. The cohorts $\left(C, C^{\prime}\right)$, 
ANO RIVER



Nuttallia olivacea

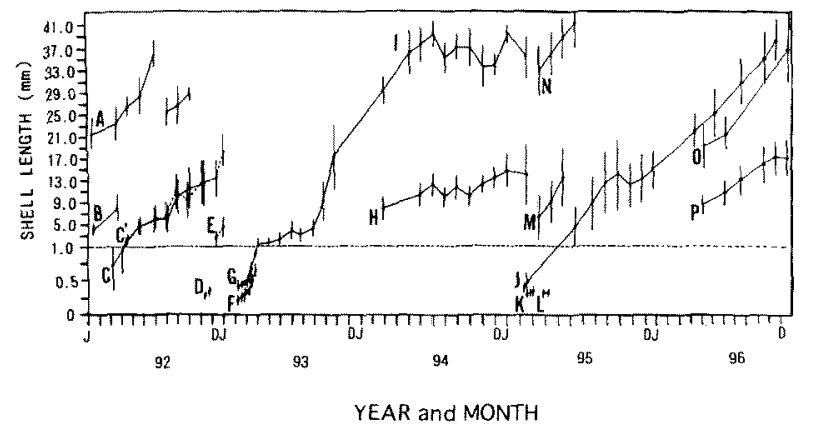

Fig. 8. Cohorts of Nuttallia olivacea populations on tidal flats of Ano River.

Symbols are same as in Fig. 7.

$(G, I, N)$ and $(J, O)$ would belong to the same one, respectively. Accordingly, in fact, a total of 13 cohorts, not $17 \mathrm{co}-$ horts as referred above, are identified. Densities of new settlers and small bivalves belonging probably to the cohorts $(\mathrm{E}, \mathrm{H}, \mathrm{M}, \mathrm{P})$ were extremely low.

Of the above 13 cohorts, a total of 5 cohorts $(A, B, C, G, J)$ succeeded in recruiting to the benthic populations. Apart from the cohorts $(A, B)$ derived probably from the populations in the year 1991, larvae of the cohorts $(C, G, J)$ settled in February and recruited in March to April: much higher densities of new settlers in February corresponded to the cohort $C$. On the other hand, larvae of the cohorts $(D, F, K, L)$ settled in winter to spring but failed to recruit. This indicates that the benthic populations of the species in the present study area were mainly sustainable by the cohorts, their larvae settling in winter and recruiting in the spring of the following year.

Occurrence periods of cohorts were mostly in the range of eleven to twenty eight months: the cohort (C) in the year 1992 with eleven months, the cohort (G-I-N) in the years 1993-1995 with twenty eight months and the cohort $(J)$ in the years 1995-1996 with twenty one months (Fig. 8). The cohorts $(C, G)$ corresponded to higher densities of new settlers and small bivalves, respectively, while the cohort (J) did not correspond to higher densities of any stage. Occurrence periods of cohorts of the species were with a much longer period as contrasted to those of $R$. philippinarum and $M$. senhousia, so that the number of the cohorts for $N$. olivacea was much smaller throughout five-year investigation than for the other two species.

\section{Discussion}

\section{Interannual Variations in Densities}

Figure 9a summarizes results of the present study arranged for each species while Fig. 9b is arranged for each life stage: 'Good' years for different life stages (planktonic larvae, new settlers, small and large bivalves) of the three species ( $R$. philippinarum, $M$. senhousia, $N$. olivacea) are defined as years with annual averages of density higher than total averages of density while 'wrong' years are defined as years with the annual averages of density lower than the total averages of density. Then, we defined 'great' peaks as samples with densities three times as high as the total averages of density. Based on Fig. 9, we can point out the following two points: First, interannual variations in densities of different life stages of the above three species, that did not correspond to each other for each species, were remarkable. Except individuals of $N$. olivacea collected in Ano River in 1990 and of $M$. senhousia collected in Shitomo River in 1994, interannual variations in densities of different life stages for each species were similar between the above two rivers. Secondly, except large bivalves, total averages of density for different life stages of the three species were similar between the rivers. On the other hand, total averages of density for large bivalves for the three species showed remarkable differences between tidal flats of the rivers: Densities of $R$. philippinarum and $M$. senhousia were much higher on the Shitomo flat while those of $N$. olivacea were much higher on the Ano flat. Total averages of densities of planktonic larvae were much biased due to 'great' peaks in 1994 and 1995, densities of $M$. senhousia larvae were higher in Ano River than in Shitomo River.

As mentioned above, interannual variations in densities of large bivalves for each species did not correspond to those of small bivalves, new settlers and also planktonic larvae of the same species in most years (Fig. 9). This indicates that interannual variations in densities of planktonic larvae, new settlers and even small bivalves, that were not leading determinants for those of large bivalves, could be caused by unpredictable environmental disturbances on the tidal flats.

Remarkable interannual variations in densities of planktonic larvae for the above three species are probably caused by several environmental factors, e.g., biological and/or abiotic factors controling size of spawning adults and also quantity of larvae supplied from it, and oceanographic conditions as a determinant of the degrees of larval retention or dispersal to the other sites or of entrainment of larvae released from the other sites. ${ }^{18,28)}$ Unfortunately, our study does not deal with these problems concerning mechanisms of larval dispersal and retention.

Environmental factors driving interannual variations in densities of new settlers, and small and large bivalves of the three species, apart from those of life stages just before the above different stages, are as follows: (1) random or selective settlement by competent larvae on different types of bottom substrata, ${ }^{3,29)}(2)$ positive or passive post-settlement movement to other sites, ${ }^{30-35)}$ (3) unpredictable environmental disturbance, e.g., high mortality in post-settlement periods due to freshwater discharges coupling with typhoons or heavy precipitation ${ }^{2,3)}$ and due to predation. ${ }^{29,36-38)}$ The above factors could generate apparent high mortality immediately after larval settlement, that has been known well for marine benthic invertebrates. ${ }^{15,25,39)}$ From our experience in field surveys in the present study area, we are able to identify several factors (e.g., fluctuations of precipitation, summer's high temperature in water 

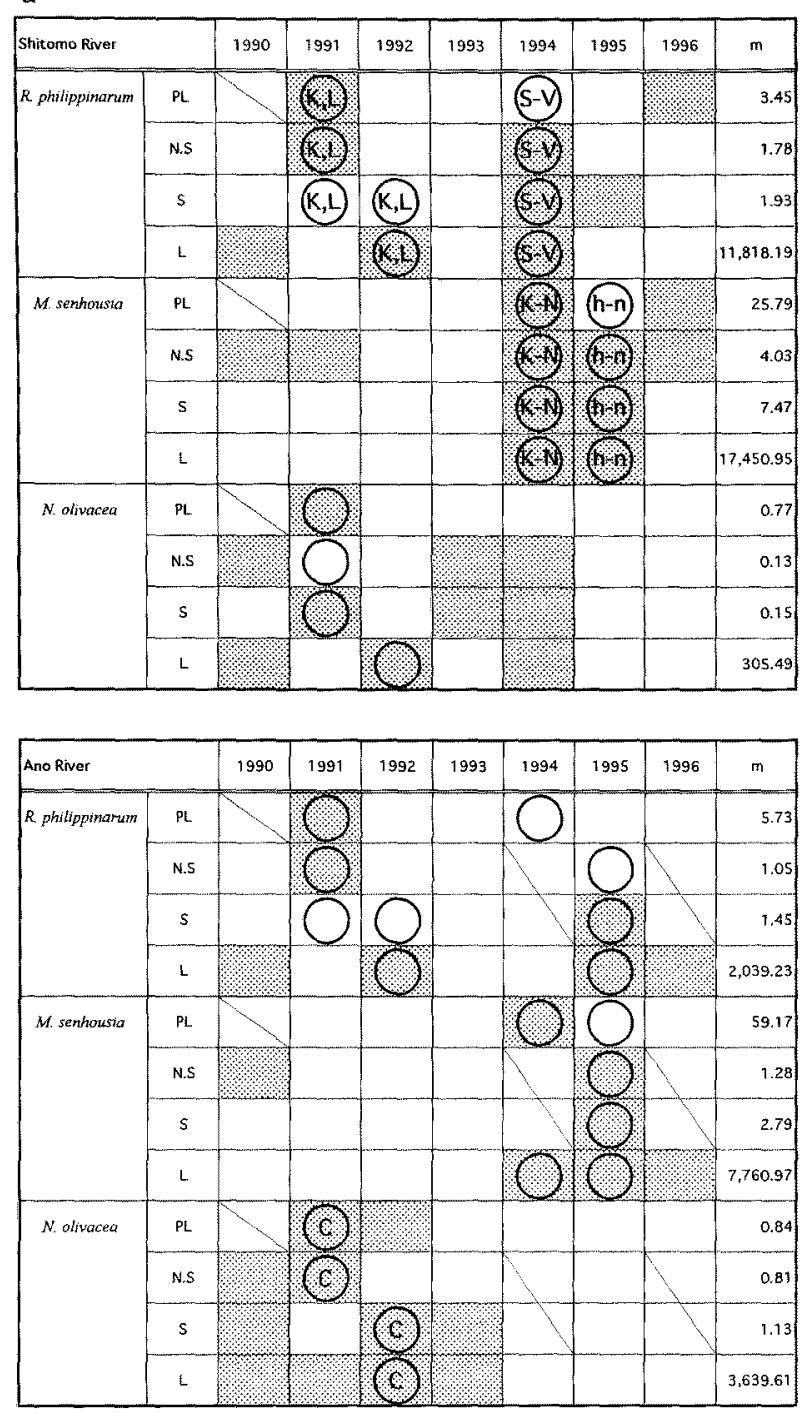

b
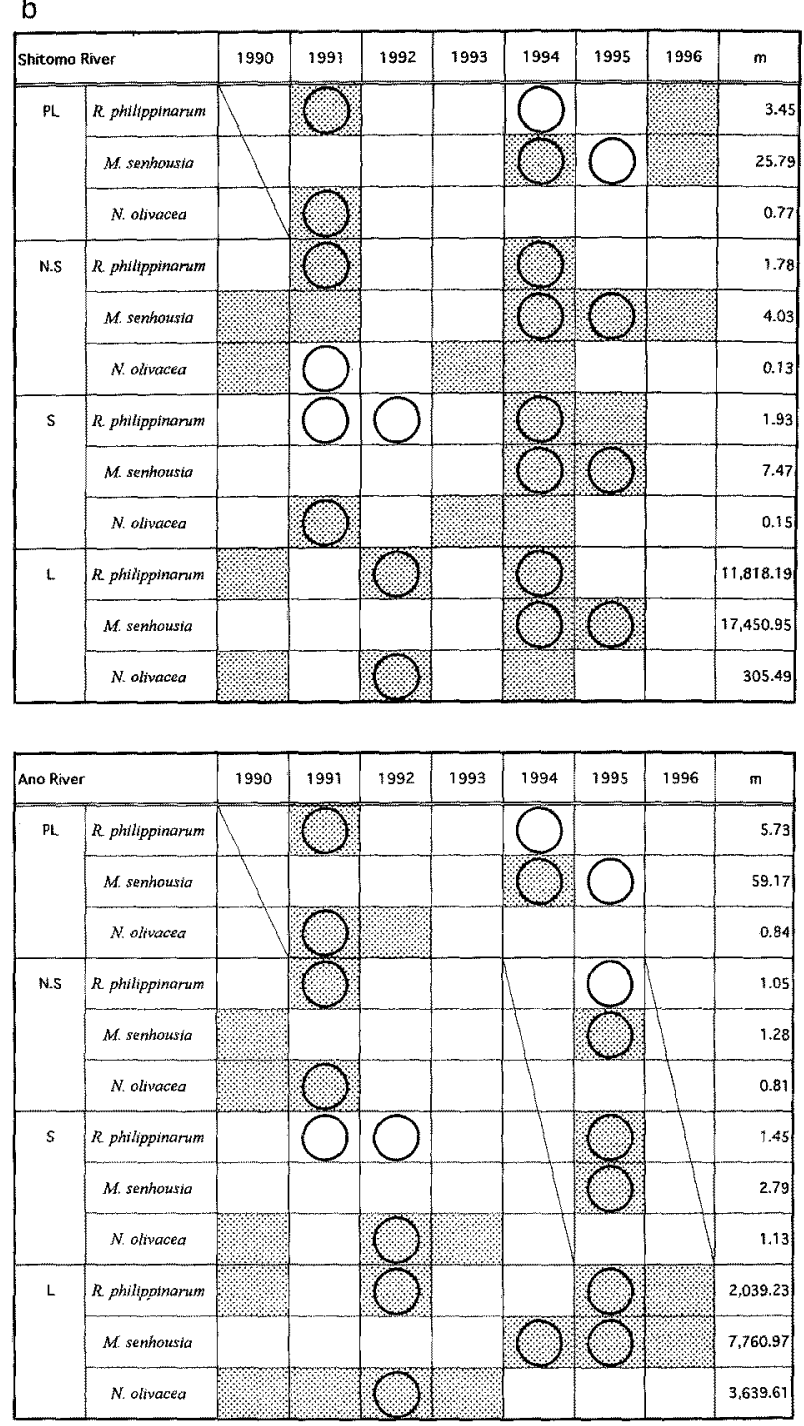

Fig. 9. Summary of long-term observations for the three bivalve species.

a: arranged according to species and then to different life stages. PL: planktonic larvae, N.S: new settlers, S: small bivalves, L: large bivalves, $m$ : total averages of densities, open circles: 'great' peaks with densities exceeding three times as total averages (m), mesh areas: years with annual averages of densities exceeding total averages of densities, alphabets: cohorts constituting 'great' peaks of densities. b: arranged according to different life stages and then to species. Symbols are same as in Fig. 9a.

and on sediment during daytime low water, and winter's low temperature in water and on sediment during midnight low water) as unpredictable environmental factors driving remarkable interannual variations in densities of different life stages for the three species.

The present study indicates as a whole that significant relationships were not detectable between densities of different life stages for the three species. However, when we turn our attention to the 'great' peaks of densities of both species $R$. philippinarum and $N$. olivacea in the year 1991 , of both species $R$. philippinarum and $M$. senhousia in 1994, and of M. senhousia in 1995 (Fig. 9), the peaks of planktonic larvae and of new settlers appear to contribute to the generation of peaks of large bivalves. Particularly in the year 1994, summer's temperature in the water exceed $30^{\circ} \mathrm{C}$ much higher than in the other years (Table 1), while total precipitation amounted to $1047 \mathrm{~mm}$ much less than $1612 \mathrm{~mm}$ of total averages of precipitation for seven-year investigation (Table 1). This suggests that 'great' peaks in 1994 would be attributed to summer's high temperature and also to low precipitation. Taking into account tidal flats coupling with unpredictable and marked environmental disturbance, these events would be driven by good fortune under unpredictable environmental disturbance.

\section{Seasonal Variations in Densities}

In Japanese waters, $R$. philippinarum have been found from Hokkaido, northern Japan, to Okinawa, southernmost Japan. Japanese populations of the species are divided into two groups, i.e., populations in the waters north of Tokyo Bay, central Japan, where the species spawns once a year in summer, and those in the water 
Table 1. Data for environmental conditions in the present study area

\begin{tabular}{|c|c|c|c|c|c|c|c|c|c|}
\hline & & 1990 & 1991 & 1992 & 1993 & 1994 & 1995 & 1996 & $m$ \\
\hline Annual Precipitation & & 1838 & 2081 & 1488 & 1895 & 1047 & 1668 & 1267 & 1612 \\
\hline \multirow{2}{*}{$\begin{array}{l}\text { Water Temperature } \\
\text { (Jan., Feb., am) }\end{array}$} & Shitomo R. & - & - & 10.5 & 9.3 & 8.4 & 8.1 & 6.6 & 8.6 \\
\hline & Ano $\mathrm{R}$. & - & - & 10.4 & 9.3 & 9.2 & 8.8 & 6.6 & 8.8 \\
\hline \multirow{2}{*}{$\begin{array}{l}\text { Water Temperature } \\
\text { (Jul., Aug., am) }\end{array}$} & Shitomo R. & - & 26.7 & 26.5 & 23.9 & 30.2 & 28.9 & 29.5 & 27.6 \\
\hline & Ano $R$ & - & 25.9 & 26.7 & 23.4 & 31.1 & 29 & 29.8 & 27.6 \\
\hline
\end{tabular}

$m$ : total averages of different environmental conditions, am and numericals in the water temperature column: annual averages of water temperature $\left({ }^{\circ} \mathrm{C}\right)$, numericals in the annual precipitation column: total quantity $(\mathrm{mm} /$ year), horizontal bars: no data.

south of the bay where the species spawns twice a year in spring and fall. ${ }^{40)}$ Apart from the present study and Sekiguchi et al ${ }^{18)}$ undertaken in Ise Bay, making clear that larvae derived from fall spawners mainly recruited in the spring of the following year, few studies have been done about whether larvae derived from spring spawners or from fall spawners would contribute to form and to maintain benthic populations of the species in Tokyo Bay and in the waters south of the bay. Studies done by Ikesue ${ }^{41}$ and Sagara ${ }^{40)}$ suggested that new settlers of the species recruting in spring, i.e., probably larvae derived from fall spawners, would contribute to sustain the populations in Tokyo and Ariake Bays, respectively.

In the present study, larvae derived from spring spawners of $R$. philippinarum also succeeded often in recruiting in summer to fall of the same year for the year 1994 and onward when summer and winter temperatures in the study area were clearly higher and lower as contrasted to before 1994, respectively (Table 1). According to Fig. 9, for two cohorts $\mathrm{K}$ and $\mathrm{L}$ constituing 'great' peaks of densities of the species, larvae settled in fall to early winter and then succeeded in recruiting in spring of the following year, while those settled in spring to summer and then succeeded in recruiting in summer to fall for cohorts $\mathrm{S}-\mathrm{V}$.

Larvae of $M$. senhousia occurred throughout the year, though those were abundant largely in summer to fall and then recruited in summer to fall of the same year. Similar results have in part been obtained by Kimura \& Sekiguchi ${ }^{21.22)}$ and Sekiguchi et al.$^{18)}$ done in Ise Bay, and by Tanaka \& Kikuchi $^{42)}$ done in Amakusa, southern Japan, though Tanaka \& Kikuchi ${ }^{42)}$ and Kimura \& Sekiguchi ${ }^{21,22)}$ did not deal with larval recruitment processes. Larvae of $N$, olivacea mainly settled in fall to winter and then recruited in spring to summer of the following year. Different from both species $R$. philippinarum and $M$. senhousia, the number of $N$. olivacea cohorts per year was extremely small with longer occurrence period sometimes exceeding a year.

Despite the above three species occurring together in the present study area, these species have life history strategies much different from each other: Both species $R$. philippina rum and $N$. olivacea live in sediment, the later species more in deep sediment, and feed or filter particles in water just above the flat sediment through siphons, ${ }^{19,20,43)}$ while $M$. senhousia forms beds on the flats, that are anchored in position at sediment using a well-developed byssus, and filter particles in water. ${ }^{21,22,44)}$ Unfortunately, it is not apparent immediately how larval recruitment processes for each species, examined in the present study, are related with different life history strategies for the three species as referred above.

\section{Differences of Dominant Bivalves Between Tidal Flats of the Rivers}

As clearly shown in the present study, densities of large bivalves of both species $R$. philippinarum and $M$. senhousia were much higher on the Shitomo flat than on the Ano flat, while the reverse was true for those of $N$. olivacea. Turning our attention to total averages of densities of different life stages of the above three species, differences in densities of large bivalves between the flats would be established in the stage of large bivalves, not in the stages from planktonic larvae to small bivalves that did not show a significant difference in densities between the rivers. Sekiguchi et al. ${ }^{18)}$ examining larval recruitment processes of bivalves on the flats same as in the present study, could get results similar to those obtained in the present study, though they have a case with densities of the larvae showing a significant difference between the rivers.

We defined 'recruitment' and/or 'large bivalves' as individuals getting shell lengths of $1.0 \mathrm{~mm}$ or more. As mentioned above, densities of large bivalves of the above three species showed remarkable differences between the rivers while those of the other life stages did not. What environmental factors or what mechanisms operated in post-settlement periods generate such differences in densities of large bivalves between the rivers? In general, $R$. philippinarum and $M$. senhousia prefer habitats with muddy sediment while $N$. olivacea prefer those with sandy sediment. ${ }^{19-22}$ Although the mouths of Ano and Shitomo Rivers are adjacent to each other, the flats of these rivers have different types of sediment, i.e., muddy sediment on the Shitomo flat where both species $R$. philippinarum and $M$. senhousia were abundant, and sandy sediment on the Ano flat where $N$. olivacea was abundant. However, as mentioned above, densities of different life stages except large bivalves did not show significant differences between the rivers. Furthermore, according to Tsutsumi \& Sekiguchi ${ }^{19)}$ examining distributional characteristics of the three species in the subtidal zone (with sandy bottom sediment) adjacent to the present study area, planktonic larvae of the three species were always found abundantly in water while the benthic stages from new settlers to large bivalves were rarely collected on bottom sediment. Thus, difference of sediment types is not attributed to directly cause density difference of large bivalves between the rivers.

Taking into account behavioral characteristics of the benthic stages of the above three species and also environ- 
mental factors operated in post-settlement periods, we devise two alternative hypotheses $(a, b)$ that explain how density differences of large bivalves of the three species are generated between the rivers as follows: (a) difference of site (river)-specific mortality: Post-recruitment mortalities of both species $R$. philippinarum and $M$. senhousia are much higher on Ano flat while those of $N$. olivacea are much higher on Shitomo flat, and (b) positive or passive movement using drifting threads and other means: Individuals in the benthic stages of both species $R$. philippinarum and $M$. senhousia move to Shitomo River through tidal transport, while those of $N$. olivacea move to Ano River. We have little information on site-specific mortality of the three species, but Luckenbach ${ }^{45}$ indicated marked difference of site-specific mortality. Movement of new settlers and also small bivalves including $R$. philippinarum using drifting threads and other means has been known..$^{31,33,34,46,47}$ It is not apparent immediately which of the above two alternative hypotheses is refuted, because we need more evidence in order to examine these hypotheses.

Acknowledgments We wish to express our sincere thanks to Drs. A. Kawamura, Y. Harada and T. Kimura, Faculty of Bioresources of Mie University, for their invaluable help and advice through the present study. Thanks are also due to Mr. M. Uchida and others of the Aquatic Ecology Laboratory of Mie University for cooperative sampling.

\section{References}

1) A. J. Underwood and P. G. Fairweather: Supply-side ecology and benthic marine assemblages. Trend. Ecol. Evol, 4, 16-20 (1989).

2) S. J. Hall: Physical disturbance and marine benthic communities: life in unconsolidated sediments. Oceanogr. Mar. Biol. Annu. Rev., 32, 179-239 (1994).

3) E. B. Olafsson, C. B. Peterson, and G. A. Ambrose: Does recruitment limitation structure populations and communities of macro-invertebrates in marine soft sediments: the relative significance of preand post-settlement processes. Oceanogr. Mar. Biol. Annu. Rev., 32, 65-109 (1994).

4) A. Sakai and H. Sekiguchi: Identification of planktonic late-stage larvae and settled bivalves in a tidal flat. Bull. Japan. Soc. Fish. Oceanogr., 56, 410-425 (1992) (in Japanese).

5) J. Roughgarden, S. Gaines, and H. Possingham: Recruitment dynamics in complex life cycles. Science, 241, 1460-1466 (1988).

6) P. K. Grosberg: Intertidal zonation of barnacles: the influence of planktonic zonation of larvae on vertical distribution of adults. Ecology, 63, 894-899 (1982).

7) P. M. Yoshioka: Role of planktonic and benthic factors in the population dynamics of the bryozoan Membranipora membranacea. Ecology, 63, 457-468 (1982).

8) H. M. Caffey: Spatial and temporal variation in settlement and recruitment of intertidal barnacles. Ecol. Monogr., 55, 313-332 (1985).

9) S. Gaines and J. Roughgarden: Larval settlement rate: a leading determinant of structure in an ecological community of the marine intertidal zone. Proc. Natl. Acad. Sci. U.S.A., 82, 3707-3711 (1985).

10) P. H. Peterson: Enhancement of Mercenaria mercenaria densities in seagrass beds: Is pattern fixed during settlement season or altered by subsequent differential survival? Limnol. Oceanogr., 31, 200205 (1986).

11) R. V. Snelgrove, C. A. Butman, and J. P. Grassle: Hydrodynamic enhancement of larval settlement in the bivalve Mulinia lateralis (Say) and the polychaete Capitella sp.1 in microdepositional environments. J. Exp. Mar. Biol. Ecol., 168, 71-109 (1993).

12) S. Gaines, S. Brown, and J. Roughgarden: Spatial variation in larval concentrations as a cause of spatial variation in settlement for the barnacle, Balanus glanula. Oecologia, 67, 267-272 (1985).
13) J. H. Connell: The consequences of variation in initial settlement vs. post-settlement mortality in rocky intertidal communities. $J$. Exp. Mar. Biol. Ecol., 93, 11-45 (1985).

14) J. P. Sutherland: Recruitment regulates demographic variation in a tropical intertidal barnacle. Ecology, 71, 955-972 (1990).

15) C. J. Hurlbut: Community recruitment: settlement and juvenile survival of seven co-occurring species of sessile marine invertebrates. Mar. Biol., 109, 507-515 (1991).

16) T. E. Minchinton and R. E. Scheibling: The influence of larval supply and settlement on the population structure of barnacle. Ecology, 72, 1867-1879 (1991).

17) G. Bachelet: Recruitment and year-to-year variability in a population of Macoma balthica (L.). Hydrobiologia, 142, 233-248 (1986).

18) H. Sekiguchi, M. Uchida, and A. Sakai: Post-settlement processes determining features of bivalve assemblages in tidal flats. Benthos Res., 49, 1-14 (1995).

19) Y. Tsutsumi and $H$. Sekiguchi: Spatial distributions of larval, newly settled, and benthic stages of bivalves in subtidal areas adjacent to tidal flats. Benthos Res., 50, 29-37 (1996a).

20) Y. Tsutsumi and H. Sekiguchi: Spatial distributions of newly settled and benthic populations of bivalves on tidal flats. Bull. Japan. Soc. Fish. Oceanogr., 60, 115-121 (1996) (in Japanese).

21) T. Kimura and H. Sekiguchi: Sorne aspects of population dynamics of a mytilid Musculista senhousia (Benson) on tidal flats. Benthos Res., 44, 29-40 (1993).

22) T. Kimura and H. Sekiguchi: Distribution of benthic animals of tidal flats in the neighbouring two rivers. Bull. Fac. Bioresources, Mie Univ., 10, 165-174 (1993) (in Japanese).

23) Y. Yoshida: Studies on larvae and young shells of industrial bivalves in Japan. J. Shimonoseki Coll. Fish., 3, 1-106 (1953) (in Japanese).

24) M. Horikoshi: Larval ecology and bioturbation. Monthly Marine Science Suppl., 1, 81-99 (1978) (in Japanese).

25) K. Muus: Settlement, growth and mortality of young bivalves in the Oresund. Ophelia, 12, 76-116 (1973).

26) A. Sakai and H. Sekiguchi: A simple method of examination on hinge apparatus in settled bivalves. Benthos Res., 39, 21-22 (1990) (in Japanese),

27) T. Akamine: Considerations of BASIC program to analyse the polymodal frequency distribution into normal distribution. Bull. Japan Sea Reg. Fish. Res. Lab., 35, 129-160 (1985) (in Japanese).

28) H. Sekiguchi: Sampling strategies vital for making clear dispersal and retention mechanisms of planktonic larvae of benthic invertebrates. Proc. 8th NRCT-JSPS Joint Seminar on Marine Science, 140-152 (1998).

29) A. N. Sastry: Pelecypoda (excluding Ostreidae), in "Reproduction of Marine Invertebrates, vol. V, Molluscs Pelecypods and Lesser Classes"' (eds. A. C. Giese and J. S. Pears), Academic Press, New York, 1979, pp. 113-292.

30) S. Hamada and T. Ino: Studies on the movement of the Japanese hard clam, Meretrix meretrix lusoria (Rording)-1. Histological studies on the gland in relation to locomotion. Nippon Suisan Gakkaishi, 20, 1-3 (1954).

31) J. B. Sigurdsson, C. W. Titman, and P. A. Davis: The dispersal of young post-larval bivalve molluscs by byssus threads. Nature, 262, 386-387 (1976).

32) R. S. Prezant and K. Chalermwat: Flotation of the bivalve Corbicula fluminea as a means of dispersal. Science, 225, 1491-1493 (1984).

33) D. J. Lane, A. R. Beamont, and J. R. Hunter: Byssus drifting and the drifting threads of the young post-larval mussel Mytitus edulis. Mar. Biol., 84, 301-308 (1985).

34) J. Beukema and J. de Vlas: Tidal-current transport of thread-drifting postlarval juveniles of the bivalve Macoma balthica from the Wadden Sea to the North Sea. Mar. Ecol. Prog. Ser., 52, 193-200 (1989).

35) W. X. Wang and Z. Z. Xu: Larval swimming and postlarval drifting behavior in the infaunal bivalve Sinonovacula constrica. Mar. Ecol. Prog. Ser., 148, 71-81 (1997).

36) R. S. Bowman and J. R. Lewis: Annual fluctuations in the recruitment of Patella vulgata L. J. Mar. Biol. Ass. U.K., 57, 793-815 (1977). 
37) H. Sekiguchi, H. Saito, and H. Nakao: Spatial and temporal distributions of planktonic and benthic phases of bivalves in a tidal estuary. Benthos Res., 40, 11-21 (1991).

38) E. F. Young, R. B. Grant, and A. Grant: A statistical study of environmental influences on bivalve recruitment in the Wash, England. Mar. Ecol. Prog. Ser., 143, 121-129 (1996).

39) G. Thorson: Reproductive and larval development of marine bottom invertebrates. Biol. Rev., 25, 1-45 (1950).

40) J. Sagara: Ecology and physiology of Ruditapes philippinarum and Meretrix lusoria. Aquabiology, 13, 102-105 (1981) (in Japanese).

41) W. Ikesue: Ecological studies on the clam, Tapes japonica (Reeve)2. On the settling season and the growth in early stage. Nippon Suisan Gakkaishi, 22, 736-741 (1957).

42) M. Tanaka and T. Kikuchi: Ecological studies on benthic macrofauna in Tomae Cove, Amakusa. 2. Production of Musculista senhousia (Bivalvia, Mytilidae). Publ. Amakusa Mar. Biol. Lab., Kyusyu
Univ., 4, 215-233 (1978).

43) A. Akiyama: Ecological function and survival strategies of benthic assemblages on tidal flats. Heredity, 39, 27-31 (1985) (in Japanese).

44) N. Ito and T. Kajihara: The ecological study of the mussel, Musculista senhousia, in Yokosuka Harbor-2. Structure of byssal threads and nests. Mar. Fouling, 3, 43-56 (1981) (in Japanese).

45) M. Luckenbach: Settlement and early post-settlement survival in the recruitment of Mulinia lateralis (Bivalvia). Mar. Ecol, Prog. Ser., 17, 245-250 (1984).

46) K. Sugawara and M. Tamaga: Floatation by drifting threads in Ruditapes philippinarum in laboratory. Nippon Suisan Gakkaishi, 18, 81-82 (1953).

47) W. J. Wolf and L. D. Wolf: Biomass and production of zoobenthos in the Grevelingen estuary, the Netherlands. Estur. Coast. Mar. Sci., 5, 1-24 (1977). 